\title{
Tenacificação do Poli(Ácido Lático) pela Adição do Terpolímero (Etileno/Acrilato de Metila/Metacrilato de Glicidila)
}

\author{
Gustavo F. Brito, Pankaj Agrawal, Edcleide M. Araújo, Tomás J. A. de Melo \\ Programa de Pós-Graduação em Ciência e Engenharia de Materiais, PPG-CEMat/UFCG
}

\begin{abstract}
Resumo: O poli(ácido lático) é um polímero biodegradável proveniente de fontes renováveis com grande potencial para substituir polímeros não biodegradáveis provenientes do petróleo. Entretanto, seu uso em determinadas aplicações é restringido devido a sua elevada fragilidade e rigidez. Com o intuito de tornar o PLA mais tenaz, o terpolímero (etileno/acrilato de metila/metacrilato de glicidila) -EMA-GMA foi adicionado ao PLA em diferentes concentrações. A adição do EMA-GMA tornou o PLA mais estável durante o processamento. Por FTIR comprovou-se a existência de reação química entre os grupos terminais do PLA e grupos do EMA-GMA. A partir dos ensaios mecânicos observou-se uma resistência ao impacto três vezes superior à do PLA puro.
\end{abstract}

Palavras-chave: Poli(ácido lático), tenacificação, terpolímero.

\section{Toughening of Polylactide by Melt Blending with an (Ethylene/Methyl Acrylate/Glycidyl Methacrylate) Terpolymer}

\begin{abstract}
The Poly(lactic acid) is a biodegradable polymer from renewable sources with potential to replace non-biodegradable polymers derived from petroleum. However its use is restricted in certain applications due to its high brittleness and rigidity. In order to make the PLA more tenacious, the terpolymer (ethylene/methyl acrylate/glycidyl methacrylate) - EMA-GMA was added to PLA in different concentrations. The addition of EMA-GMA to PLA turned the blends more stable during processing. The FTIR data confirmed the chemical reaction between groups in PLA and the EMA-GMA. A three fold increase was observed in the impact strength compared to pure PLA.
\end{abstract}

Keywords: Poly(lactic acid), toughening, terpolymer.

\section{Introdução}

O uso e o descarte indevidos dos materiais plásticos, aliados a sua resistência a degradação acabam gerando problemas ambientais sérios ${ }^{[1]}$. Por este motivo, polímeros biodegradáveis têm atraído grande atenção no mundo inteiro, tanto do ponto de vista científico como tecnológico ${ }^{[2]}$. Alguns desses polímeros possuem propriedades que possibilitam sua aplicação em produtos confeccionados a partir de polímeros provenientes do petróleo ${ }^{[3]}$. Características como durabilidade durante o uso e degradabilidade após o descarte tornam esses materiais uma classe atraente, pois possibilita minimizar problemas ambientais e ao mesmo tempo atender às exigências do mercado, assim, muito se têm investido nessa nova classe de polímeros ${ }^{[4]}$. O poli(ácido lático) - PLA é um poliéster alifático produzido por síntese química a partir de ácido láctico obtido por fermentação bacteriana de glicose extraída do milho, fonte renovável. O mesmo é um polímero termoplástico, semicristalino ou amorfo, biocompatível e biodegradável, com uso potencial na confecção de embalagens, itens de descarte rápido, fibras têxteis e diversas aplicações na área médica ${ }^{[5-7]}$. Entretanto, o PLA possui elevada fragilidade e rigidez o que o impede de ser utilizado em algumas aplicações ${ }^{[8,9]}$. A maneira mais prática e econômica de superar a fragilidade e rigidez do PLA é pela confecção de blendas por fusão ${ }^{[8]}$. Desta forma, blendas de PLA com diversos polímeros biodegradáveis e não biodegradáveis, têm sido confeccionadas para melhorar as propriedades do PLA ${ }^{[8-14]}$. Entretanto a maioria das blendas são imiscíveis apresentando propriedades que não são adequadas para aplicações industriais, ou seja, são incompatíveis ${ }^{[15]}$. Para superar a imiscibilidade é necessário a adição de um compatibilizante, copolímero em bloco ou enxertado, que podem ser pré-fabricados ou formados in situ durante compatibilização reativa formando copolímeros na interface ${ }^{[8,10,15,16]}$. A literatura reporta que o anel epóxi presente no metacrilato de glicidila (GMA) pode reagir com grupos hidroxilas e carboxilas, sendo a reação com os grupos carboxila mais reativa do que com os grupos hidroxila. O PLA possui grupos terminais carboxilas e hidroxilas, fazendo do GMA uma alternativa potencial para compatibilização de suas blendas ${ }^{[8,17-21]}$. A Figura 1 ilustra as possíveis reações entre o anel epóxi do metacrilato de glicidila e os grupos terminais carboxilas e hidroxilas do PLA ${ }^{[17]}$.

Neste trabalho blendas de PLA/EMA-GMA com diferentes concentrações do terpolímero (etileno/acrilato de metila/metacrilato de glicidila), EMA-GMA, foram produzidas por fusão, com o objetivo de se avaliar o efeito das diferentes concentrações de EMA-GMA na tenacificação do PLA. Para isto, as blendas confeccionadas foram analisadas por reometria de torque, FTIR, MEV e ensaios mecânicos.

\section{Experimental}

\section{Materiais}

Poli(ácido lático) - PLA2002D, NatureWorks ${ }^{\circledR}$, Cargill. Densidade relativa de $1,24, \mathrm{IF}=4-8 \mathrm{~g} / 10 \mathrm{~min}\left(190{ }^{\circ} \mathrm{C} / 2,16 \mathrm{~kg}\right)$, $\mathrm{Tg}=58{ }^{\circ} \mathrm{C}$ e $\mathrm{Tm}=153{ }^{\circ} \mathrm{C}$, módulo de Young, $\mathrm{E}=3,5 \mathrm{GPa}$. Terpolímero (etileno/acrilato de metila/metacrilato de glicidila), EMA-GMA, contendo $24 \%$ acrilato de metila e $8 \%$ de metacrilato de glicidila, Lotader ${ }^{\circledR}$ AX8900, Arkema. Densidade de $0,95 \mathrm{~g} . \mathrm{cm}^{3}$, IF $=6 \mathrm{~g} / 10 \mathrm{~min}\left(190{ }^{\circ} \mathrm{C} / 2,16 \mathrm{~kg}\right)$, módulo de Young, $\mathrm{E}=8 \mathrm{MPa}$. A Figura 2 apresenta as estruturas moleculares do (a) PLA e do (b) EMA-GMA.

Autor para correspondência: Tomás J. A. de Melo, Departamento de Engenharia de Materiais, Universidade Federal de Campina Grande - UFCG, 


\section{Métodos}

Antes de ser utilizado na confecção das blendas, o PLA foi secado em estufa a vácuo a $80{ }^{\circ} \mathrm{C}$ durante 4 horas, como sugerido pelo fabricante. Em seguida, o PLA e o EMA-GMA foram misturados a frio de forma manual para promover uma melhor homogeneização e em seguida a mistura foi alimentada em uma extrusora dupla-rosca, cônica, contra-rotacional, acoplada a um equipamento Haake System 90 . O perfil de temperatura utilizado foi de $100{ }^{\circ} \mathrm{C}-170{ }^{\circ} \mathrm{C}-180{ }^{\circ} \mathrm{C}-180{ }^{\circ} \mathrm{C}-180{ }^{\circ} \mathrm{C}$ com velocidade de rosca a $50 \mathrm{rpm}$. Após extrusado o material foi granulado e secado a $80{ }^{\circ} \mathrm{C}$ em estufa a vácuo durante 12 horas. As blendas obtidas foram então moldadas por injeção para obtenção de corpos de prova de tração e impacto confeccionados segundo a norma ASTM. Para isto foi utilizada uma injetora Fluidmec, Modelo H3040. A temperatura de moldagem foi de $160{ }^{\circ} \mathrm{C}$ e a temperatura do molde de $20^{\circ} \mathrm{C}$. A Figura 3 ilustra o processo utilizado para obtenção das blendas PLA/EMA-GMA ${ }^{[17]}$.

Para o estudo reológico por reometria de torque foi utilizado um misturador fechado Rheocord 600 acoplado a um equipamento Haake System 90, com rotores do tipo roller operando a uma velocidade de $50 \mathrm{rpm}$ e temperatura de $180{ }^{\circ} \mathrm{C}$, sob atmosfera de ar durante 20 minutos.

As análises por espectroscopia na região do infravermelho por transformada de Fourier (FTIR), foram realizadas em um espectômetro de infravermelho de marca PerkinElmer, modelo Spectrum 400 FT Mid-IR, operando no modo de reflexão total atenuada (ATR). As amostras foram caracterizadas em forma de pó o qual foi obtido a partir dos corpos de prova.

Os ensaios de tração foram realizados em um equipamento AG-IS da Shimadzu, operando a uma velocidade de deformação de $50 \mathrm{~mm} / \mathrm{min}$, de acordo com a norma ASTM D638, em

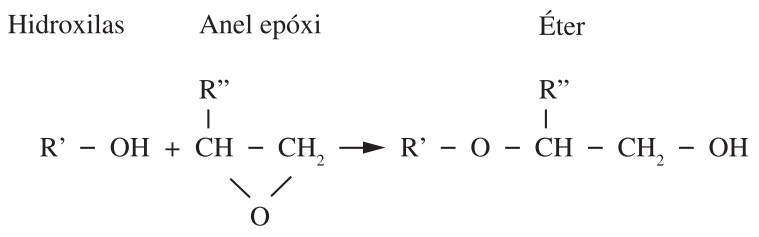

(a)

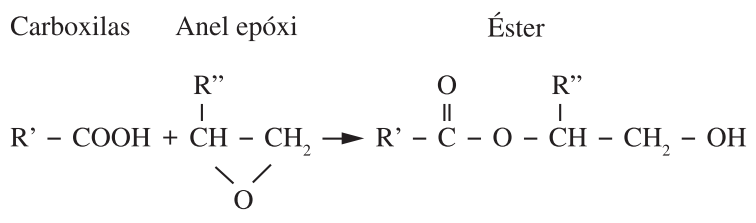

(b)

Figura 1. Reações do grupo epóxi do GMA com os grupos terminais a) hidroxilas e; b) carboxilas do PLA. temperatura ambiente. Os ensaios de impacto Izod foram realizados em corpos de prova entalhados, utilizando-se um equipamento do tipo Resil 5,5 da Ceast e pêndulo de 2,75 J, de acordo com a norma ASTM D256, em temperatura ambiente. Os entalhes de $2,5 \mathrm{~mm}$ foram feitos em um entalhador Notschvis da Ceast. Os resultados foram obtidos a partir de uma média de 5 corpos de prova. As superfícies de fratura dos corpos de prova submetidos ao ensaio de impacto foram recobertas com ouro e analisadas em um microscópio eletrônico de varredura, Shimadzu SSX-550 Superscan, a uma voltagem de $15 \mathrm{kV}$, sob alto vácuo.

\section{Resultados e Discussão}

\section{Reometria de torque}

Estudos por reometria de torque foram realizados para o PLA puro, o EMA-GMA e blendas PLA/EMA-GMA, onde a concentração de EMA-GMA foi variada em 10, 20 e 30\% em massa. As curvas de mudança do torque em função do tempo para o PLA o EMA-GMA, e as blendas são apresentadas na Figura 4, a partir da qual se observa que a processabilidade do PLA é alterada pela presença do EMA-GMA. A curva do PLA puro decai gradativamente durante o processamento enquanto que a curva do EMA-GMA apresenta estabilidade. A diminuição do torque do PLA em função do tempo de processamento, à temperatura e velocidade constante dos rotores, indica que o material pode estar se degradando por quebra de ligações na cadeia principal ${ }^{[22]}$. Nas blendas, observa-se que o torque apresenta tendência de estabilidade com o tempo com o aumento da concentração de EMA-GMA, portanto pode-se inferir que este efeito pode está relacionado com a ocorrência de reações entre os grupos funcionais dos componentes da blenda conforme ilustrado na Figura 1. Deve ser considerado que nos processos de transformação industrial, o tempo de residência do material nas máquinas é inferior ao utilizado nesta pesquisa.

\section{Espectroscopia na região do infravermelho por Transformada de Fourier (FTIR)}

Os espectros do PLA, do EMA-GMA e das blendas PLA/EMA-GMA obtidos por FTIR são ilustrados na Figura 5. A presença do anel epóxi presente nos grupos metacrilato de glicidila (GMA) do EMA-GMA é caracterizada pela existência de uma banda a localizada entre $910-915 \mathrm{~cm}^{-1}$, correspondente a contração das ligações C-C, enquanto as ligações C-O estiram. Esta banda desaparece completamente após a abertura do anel epóxi durante a reação ${ }^{[23-25]}$. A banda do anel epóxi pode ser visualizada na Figura 5, indicada por uma seta, no espectro do EMA-GMA. É possível observar o desaparecimento da banda a $912 \mathrm{~cm}^{-1}$ para as blendas<smiles>CC(C)OC(=O)C(C)O</smiles>

(a)

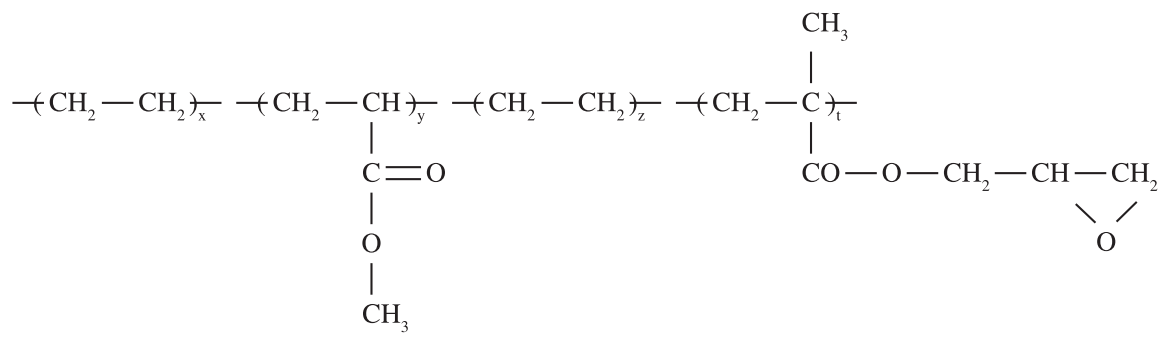

(b)

Figura 2. Estruturas moleculares do a) PLA e do b) EMA-GMA. 


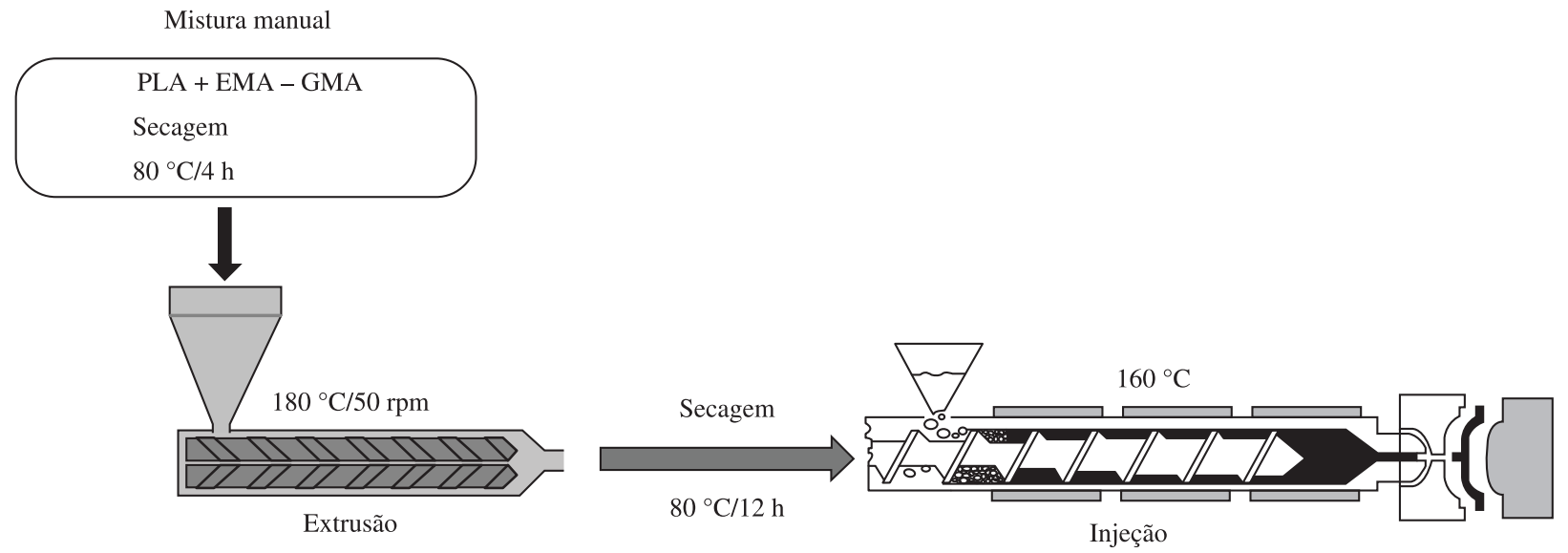

Figura 3. Processo utilizado para obtenção das blendas PLA/EMA-GMA.

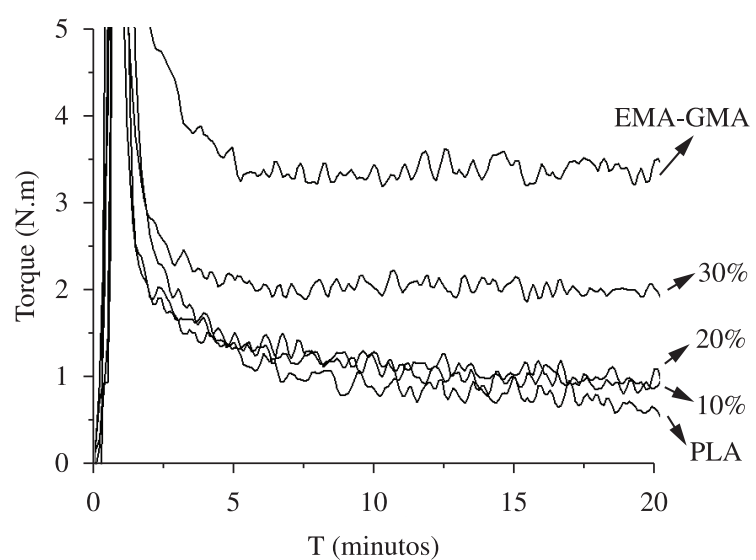

Figura 4. Variação do torque com o tempo para diferentes concentrações de EMA-GMA no PLA.

PLA/EMA-GMA, o que evidencia a ocorrência de reação entre anel epóxi presente no EMA-GMA e os grupos terminais carboxilas e/ ou hidroxilas do PLA.

\section{Morfologia}

Para o estudo da morfologia, fotomicrografias foram obtidas por MEV a partir das superfícies de fratura dos corpos de prova de impacto do PLA puro e das blendas PLA/EMA-GMA. A Figura 6a apresenta a superfície de fratura do PLA puro, a qual exibe aspecto de fratura frágil, sem deformação plástica aparente. Para a blenda PLA/EMA-GMA (95/5), Figura 6b, poucas partículas da fase dispersa, EMA-GMA, são observadas na matriz do PLA, as quais se encontram largamente distanciadas. Para a blenda PLA/EMA-GMA (87,5/12,5), Figura 6c, observa-se que a mesma apresenta menor tamanho de partículas da fase dispersa que as demais blendas e que as partículas se encontram bem dispersas por toda matriz, apresentando também menor distância entre partículas. Para a blenda PLA/EMA-GMA (80/20), Figura 6d, observa-se ampla faixa de variação do tamanho de partículas da fase dispersa. Provavelmente o acréscimo da concentração de EMA-GMA, ocasionou a coalescência de suas partículas. De acordo com estes resultados, para o sistema em estudo e as condições de processamento utilizadas, existe o indicativo de



Figura 5. Espectros de FTIR para as blendas PLA/EMA-GMA na região do anel epóxi.

uma concentração crítica de EMA-GMA para obtenção de um tamanho ótimo de partículas da fase dispersa. Com o aumento de 5 para 12,5\% na concentração de EMA-GMA, o tamanho das partículas de EMA-GMA tendem a diminuir e dispersarem melhor na matriz de PLA. Entretanto, com o aumento de 12,5 para $20 \%$ na concentração de EMA-GMA, as partículas de EMA-GMA tendem a coalescer, aumentando de tamanho, e uma ampla faixa de distribuição de tamanho de partículas é observada na matriz de PLA. Estas observações foram feitas em várias fotomicrografias obtidas de cada amostra. Segundo Bucknall \& Paul ${ }^{[26]}$ e Liu ${ }^{[27]}$ para determinado sistema, existe um tamanho ótimo de partículas da fase dispersa para que uma tenacificação eficiente seja atingida.

\section{Propriedades mecânicas}

Os valores de módulo, resistência a tração e resistência ao impacto, obtidos a partir dos ensaios mecânicos realizados para o PLA puro e blendas PLA/EMA-GMA, são apresentados na Figura 7. A adição de EMA-GMA, polímero flexível com módulo de $8 \mathrm{MPa}$, ao PLA, faz com que o valor do módulo do PLA decresça, e esse decréscimo aumenta à medida que a concentração de EMA-GMA aumenta, como ilustra a Figura 7a. Para as blendas os valores dos módulos foram inferiores ao do PLA puro indicando que materiais menos rígidos foram 


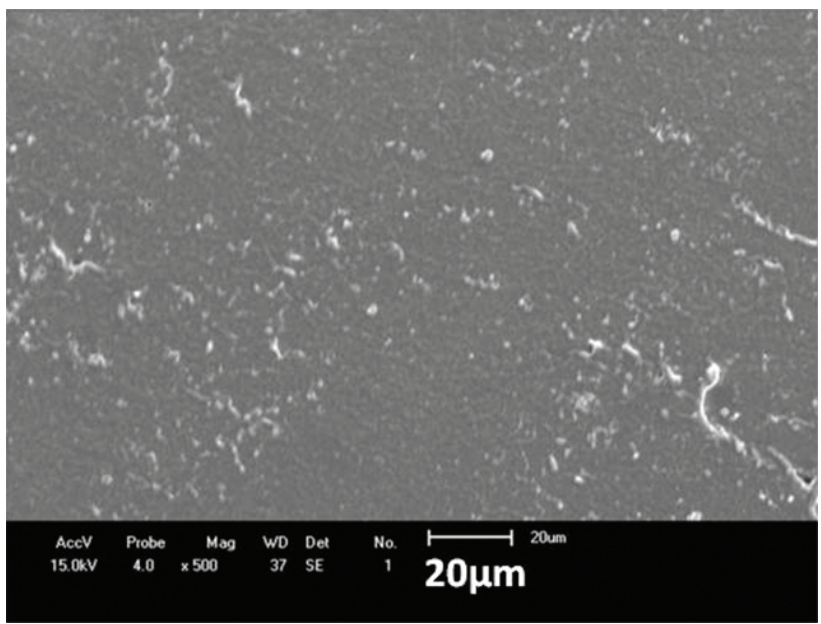

(a)

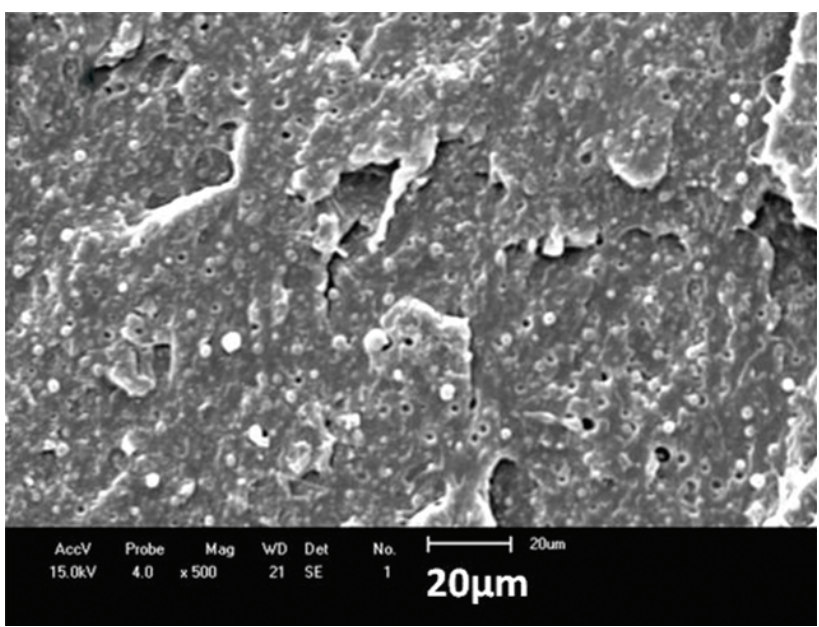

(c)

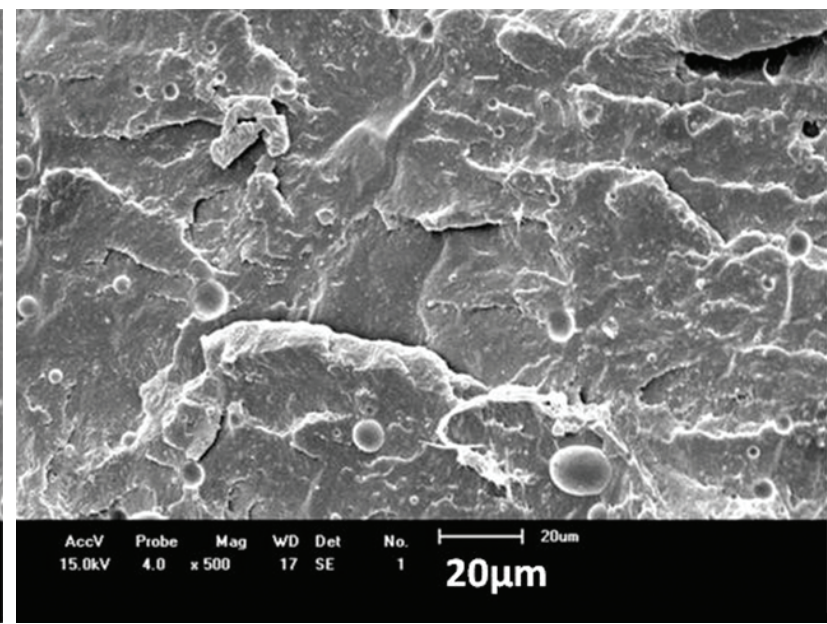

(b)

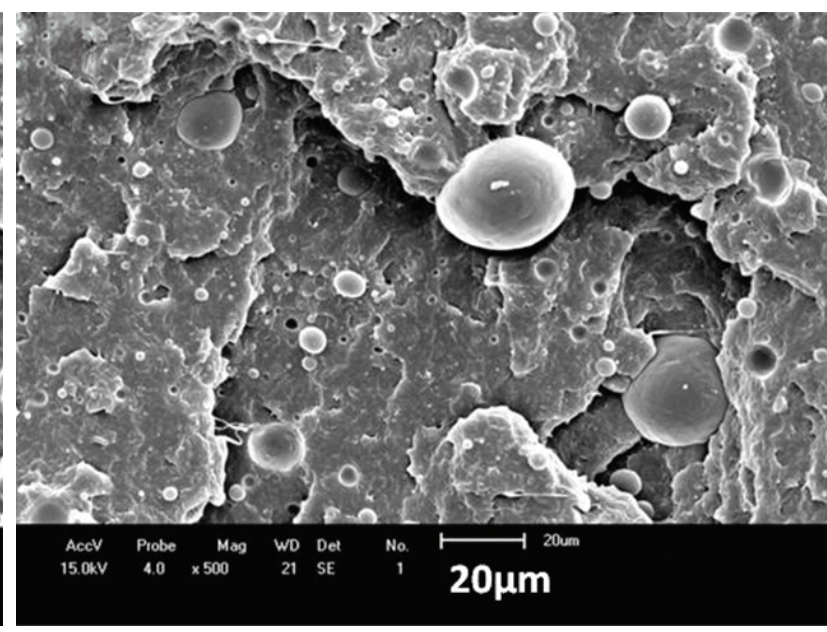

(d)

Figura 6. Fotomicrografias obtidas por MEV para: a) PLA puro; b) PLA/EMA-GMA (95/5); c) PLA/EMA-GMA (87,5/12,5) e; d) PLA/EMA-GMA (80/20). Aumento de 500x.

obtidos. Assim como para o módulo, a adição de EMA-GMA causa diminuição da resistência à tração das blendas com relação ao PLA puro, como ilustra a Figura $7 \mathrm{~b}$, sendo esta diminuição também inversamente proporcional a concentração de EMA-GMA. Por outro lado, a resistência ao impacto (R.I.) para todas as blendas foi maior que para o PLA puro, como ilustra a Figura 7c. Além disso, evidencia-se que a R.I. aumenta quando a concentração de EMA-GMA aumenta de 5 para $12,5 \%$, porém decresce quando a concentração aumenta de 12,5 para $20 \%$, o que indica a existência de uma concentração crítica de EMA-GMA para obtenção de um tamanho ótimo de partículas, como discutido anteriormente para a morfologia, o que acarretará na obtenção da máxima R.I. para o sistema em estudo, nas condições de processamento utilizadas. Em concordância com os dados apresentados, Fu et al. ${ }^{[28]}$ afirmaram que durante a fratura o movimento da trinca é momentaneamente retardado nas regiões onde estão presente heterogeneidades dentro da matriz, que neste caso são as partículas de EMA-GMA, promovendo maior tenacificação, a qual é conseguida quando as partículas dispersas se tornam próximas o bastante para interagirem efetivamente com a trinca.

As curvas tensão-deformação do PLA puro e blendas PLA/EMA-GMA, são ilustradas na Figura 8. Observa-se que o
PLA puro apresentou pouco alongamento até a ruptura, 2,7\%, inerente a sua fragilidade. Sua tenacidade, energia absorvida pelo material até a ruptura, medida pela área sob a curva foi de 4,55 J. A blenda PLA/EMA-GMA (95/5) apresentou alongamento até a ruptura de $2 \%$ e tenacidade de 2,6 J, valores inferiores ao do PLA. Provavelmente para esta blenda o tamanho das partículas e a distância entre as mesmas não foram eficazes em ativar os mecanismos de tenacificação. Desta forma as partículas agiram primeiramente como concentradoras de tensão iniciando a propagação de trincas instáveis, conforme inferido em trabalho anterior $^{[26]}$. A blenda PLA/EMA-GMA $(87,5 / 12,5)$ apresentou alongamento até a ruptura de $3,9 \%$ e tenacidade de 5,7 J, e a blenda PLA/EMA-GMA (80/20) apresentou alongamento até a ruptura de $6,4 \%$ e tenacidade de $6,5 \mathrm{~J}$. Pode-se concluir que, para as blendas, tanto o alongamento até a ruptura como a tenacidade aumentam à medida que a concentração de EMA-GMA é aumentada.

Diferentemente da resistência ao impacto, as propriedades de alongamento até a ruptura e tenacidade não se apresentam dependentes de uma concentração crítica de EMA-GMA, porém deve ser levadas em consideração que, tais propriedades são medidas em diferentes tipos de ensaios, dinâmico para a R.I. e 


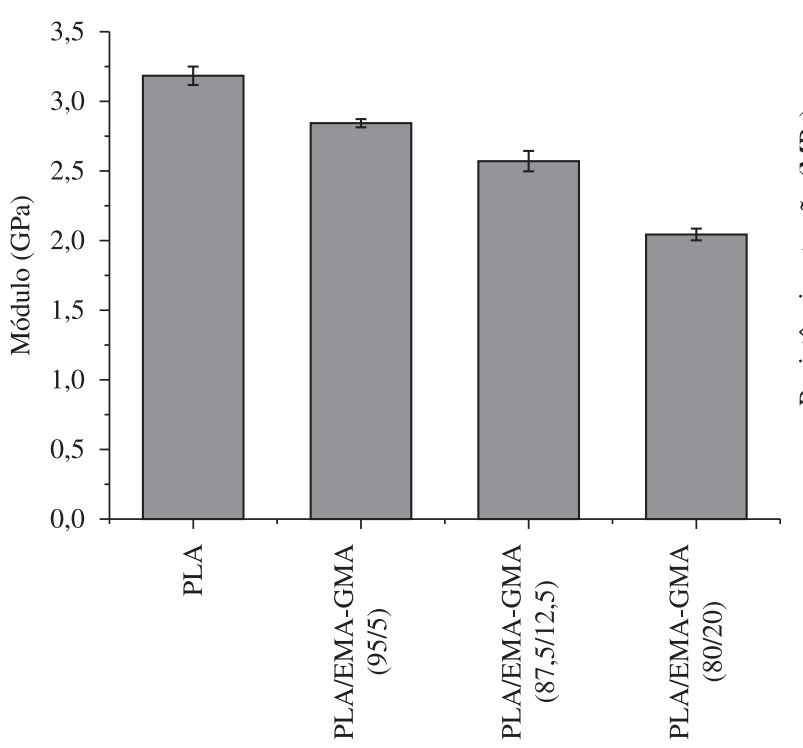

(a)

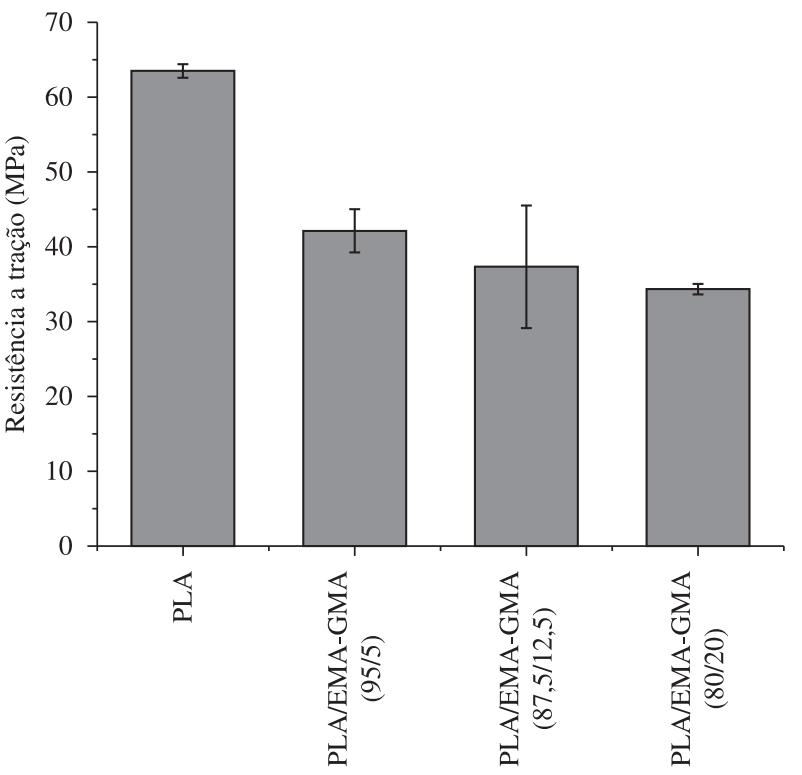

(b)

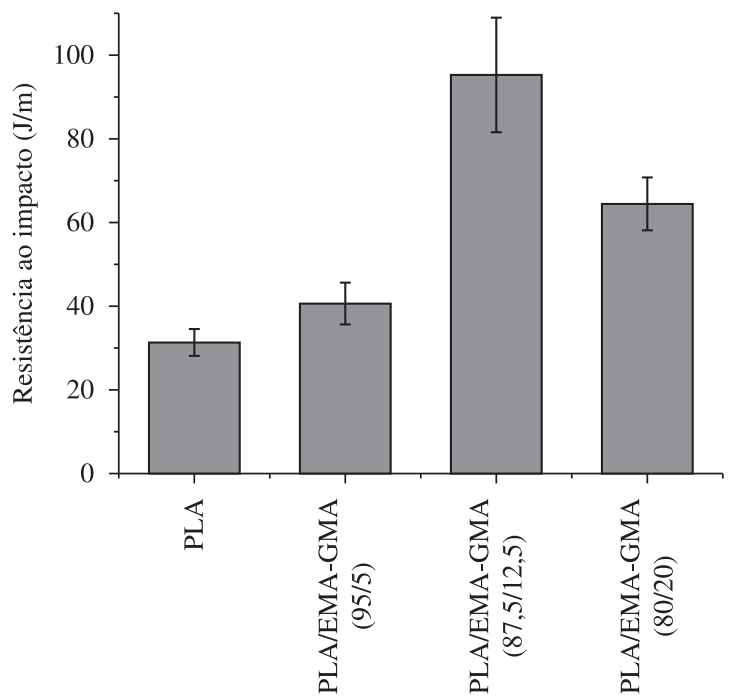

(c)

Figura 7. Módulo a) resistência a tração; b) e resistência ao impacto; e; c) do PLA puro e das blendas PLA/EMA-GMA.

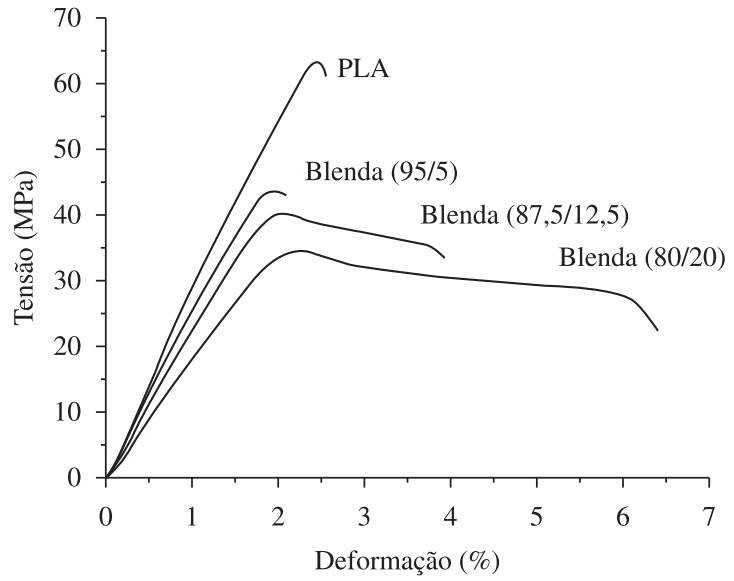

Figura 8. Curvas tensão-deformação do PLA puro e das blendas PLA/ EMA-GMA. estático para o alongamento até a ruptura e tenacidade, nos quais atuam diferentes mecanismos de tenacificação.

\section{Conclusões}

Neste trabalho foi investigada a influência do terpolímero EMA-GMA no processamento e nas propriedades mecânicas e morfológicas do PLA. A processabilidade do PLA foi alterada pela adição de EMA-GMA, tornando as blendas mais estáveis durante o processamento do que o PLA puro, sendo as blendas com maior teor de EMA-GMA mais estáveis. Os grupos terminais carboxilas e hidroxilas do PLA reagiram com o anel epóxi presente no EMA-GMA, como evidenciado por FTIR, promovendo boa interação entre os componentes das blendas, levando a obtenção de boas propriedades mecânicas. A partir das análises morfológicas e dos ensaios mecânicos evidenciou-se que materiais menos rígidos e frágeis foram obtidos, chegando-se a obter uma resistência ao impacto três vezes superior a do PLA puro. 


\section{Agradecimentos}

Os autores agradecem a CAPES e ao CNPq pelo auxílio financeiro, a empresa Arkema na pessoa do Eng. Aldo Silvio, pela doação do Lotader, e a empresa Cargill pela doação do PLA.

\section{Referências Bibliográficas}

1. Faria, A. U. \& Franchetti, S. M. M. - Polímeros, 20, p.141 (2010). http://dx.doi.org/10.1590/S0104-14282010005000024

2. Machado, M. L. C.; Pereira, N. C.; Miranda, L. F.; Terence, M. C. \& Pradella, J. G. C. - Polímeros, 20, p.19 (2010).

3. Campos, A.; Marconato, J. C. \& Franchetti, S. M. M. - Polímeros, 20, p.295 (2010). http://dx.doi.org/10.1590/S0104-14282010005000039

4. Pellicano, M.; Pachekoski, W. \& Agnelli, J. A. M. - Polímeros, 19, p.212 (2009). http://dx.doi.org/10.1590/S0104-14282009000300009

5. Rudnik, E. - "Compostable Polymer Materials", Elsevier, Oxford (2008).

6. Zhang, J. F. \& Sun, X. - "Poly(lactic acid)-based bioplastics", in: Biodegradable Polymers for Industrial Application, cap.10, Ray Smith (ed.), Woodhead Publishing, Cambridge (2005). http://dx.doi. org/10.1533/9781845690762.2.251

7. Barcellos, I. O.; Andreaus, J.; Battisti, A. M. \& Borges, J. K. - Polímeros, 18, p.256 (2008).

8. Liu, H.; Chen, F.; Liu, B.; Estep, G. \& Zhang, J. - Macromolecules, 43, p.6058 (2010). http://dx.doi.org/10.1021/ma101108g

9. Kumar, M.; Mohanty, S.; Nayak, S. K. \& Parvaiz, M. R. - Bioresource Technology, 101, p.8406 (2010). PMid:20573502. http://dx.doi. org/10.1016/j.biortech.2010.05.075

10. Oyama, H.T. - Polymer, 50, p.747 (2009). http://dx.doi.org/10.1016/j. polymer.2008.12.025

11. Balakrishnan, H.; Hassan, A.; Wahit, M. U.; Yussuf A. A. \& Razak, S. B. A. - Materials and Design, 31, p.3289 (2010). http://dx.doi. org/10.1016/j.matdes.2010.02.008

12. Focarete, M. L.; Scandola, M.; Dobrzynski, P. \& Kowalczuk, M. - Macromolecules, 35, p.8472 (2002). http://dx.doi.org/10.1021/ $\mathrm{ma} 020940 \mathrm{z}$

13. Yoon, C. S. \& Ji, D. S. - Fibers and Polymers, 4, p.59 (2003). http:// dx.doi.org/10.1007/BF02875438

14. Jiang, L.; Wolcott, M. P. \& Zhang, J. W. - Biomacromolecules, 7, p.199 (2006). PMid:16398516. http://dx.doi.org/10.1021/bm050581q
15. Agrawal, P.; Araújo, E. M. \& Mélo, T. J. A. - Polímeors, 18, p.152 (2008).

16. Brito, G. F.; Agrawal, P.; Cunha, C. T. C.; Araújo, E. M. \& Mélo, T. J. A. - "Toughened Poly(Lactic Acid): Mechanical and Morphological Characterizations", in: Anais do TMS 2011, San Diego, fev/mar (2011).

17. Brito, G. F. - "Tenacificação do Biopolímero Poli(Ácido Lático) com adição de Modificadores de Impacto e de Argila”, Dissertação de Mestrado, Universidade Federal de Campina Grande, Brasil (2011).

18. Juntuek, P.; Ruksakulpiwat, C.; Humsamrong, P. \& Ruksakulpiwat Y. - Clean Technol., p. 302 (2010).

19. Kumar, M.; Mohanty, S.; Nayak, S. K. \& Parvaiz, M. R. - Biores. Technol., 101, p.8406 (2010). PMid:20573502. http://dx.doi. org/10.1016/j.biortech.2010.05.075

20. Reis, A. V.; Fajardo, A. R.; Schuquel, I. T. A.; Guilherme, M. R.; Vidotti, G. J.; Rubira, A. F. \& Muniz, E. C. - J. Org. Chem., 74, p.3750 (2009). PMid:19361172. http://dx.doi.org/10.1021/jo900033c

21. Su, Z.; Li, Q.; Liu, Y.; Hu, G. \& Wu, C. - Eur. Polym. J., 45, p.2428 (2009).

22. De Paoli, M. A. - "Degradação e Estabilização de Polímeros", Artliber (2008).

23. Zacharuk, M. - "Nanocompósitos epóxi/ncpm funcionalizados com polietileno glicol", Dissertação de Mestrado, Universidade do Estado de Santa Catarina, Brasil (2009).

24. Khamwichit, A. - "Toughening of Polyester-Based Polymers via Reactive Compatibilization", Tese de Doutorado, The University of Texas, United States (2006).

25. Lee, H. \& Neville, K. - "Handbook of Epoxy Resins", McGraw-Hill, New York (1967).

26. Bucknall, C. B. \& Paul, D. R. - Polymer, 50, p.5539 (2009). http:// dx.doi.org/10.1016/j.polymer.2009.09.059

27. Liu, H.; Song, W.; Chen, F.; Guo, L. \& Zhang, J. - Macromolecules, 44, p.1513 (2011).

28. Fu, S. Y.; Feng, X. Q.; Lauke, B. \& Mai, Y.W. -Compos. Part B: eng., 39, p.933 (2008). http://dx.doi.org/10.1016/j.compositesb.2008.01.002

Enviado: 02/06/11

Reenviado: 20/07/11

Aceito: $26 / 07 / 11$ 